\title{
A Cooperative Synchronous Observation of Winds and Tides in the Tropical Lower Stratosphere and Mesosphere Using VHF Radars at Jicamarca and Arecibo
}

\author{
Yasuyuki MAeKAWA ${ }^{1) *}$, Takehiko AsO $^{2)}$, Jürgen RöTtGeR ${ }^{3), 4)}$, \\ Peter CZECHOWSKY ${ }^{4)}$, Rüdiger RÜSTER ${ }^{4}$, Gerhard SCHMIDT ${ }^{4)}$, \\ Isamu Hirota ${ }^{5)}$, Ronald F. WoOdMAN ${ }^{6}$, and Susumu KATO ${ }^{1)}$ \\ ${ }^{1)}$ Radio Atmospheric Science Center, Kyoto University, Uji, Japan \\ ${ }^{2)}$ Department of Electrical Engineering, Kyoto University, Kyoto, Japan \\ 3) Arecibo Observatory, National Astronomy and Ionosphere Center, Arecibo, \\ Puerto Rico 00612, U.S.A. \\ ${ }^{4)}$ Max-Planck-Institut für Aeronomie, 3411 Kaltenburg-Lindau 3, Fed. Rep. Germany \\ ${ }^{5)}$ Geophysical Institute, Kyoto University, Kyoto, Japan \\ ${ }^{6}$ Instituto Geofisico del Peru, Sector Education, Lima 100, Peru
}

(Received April 6, 1985; Revised October 28, 1985)

\begin{abstract}
A cooperative synchronous observation of winds in the tropical lower stratosphere and mesosphere was carried out using VHF radars at Jicamarca $\left(11.95^{\circ} \mathrm{S}, 76.87^{\circ} \mathrm{W}\right)$ and at Arecibo $\left(18.35^{\circ} \mathrm{N}, 66.75^{\circ} \mathrm{W}\right)$ on $19-21$ or 23 November 1981. The comparison between observations about symmetrical north and south of the equator is focussed on the mean and tidal wind characteristics. Vertical structures of the mean zonal winds at both observational stations are in fairly good agreement with the CIRA (1972) zonal circulation model at the corresponding latitudes. The nature of lower stratospheric diurnal tides is similar between Jicamarca and Arecibo. Their vertical profiles generally correspond to the theoretical predictions based on the fundamental tidal modes. The vertical scale of the tidal components including higher-order modes is shown to be longer than $10 \mathrm{~km}$. In the mesosphere, vertically propagating diurnal tide which is expected to be predominant at lower latitudes is partially detected in daytime at Arecibo, while it is not so well-defined at Jicamarca, suggesting a variable nature of the relevant tidal modes.
\end{abstract}

\section{Introduction}

In recent years, long period observations of atmospheric tides in the upper mesosphere and lower thermosphere are performed by means of meteor radars (e.g., TSUDA et al., 1983; AHMED and ROPER, 1983) and medium frequency (MF) radars (e.g., MANSON et al., 1983). Nevertheless, complete vertical structure of

*Present affiliation: Faculty of Engineering, Osaka Electro-Communication University, Neyagawa, Japan. 
tides from the ground to the thermosphere is not so well understood, compared with the recent development of realistic theoretical studies (see a review of KATO (1981), for example). In this connection, the high-power VHF/UHF radar techniques are expected to be a powerful tool for investigating the nature of tides in the stratosphere and mesosphere.

In order to reveal the global configuration of tides such as longitudinal wavenumbers and dominant Hough modes, it is necessary to compare the tidal motions observed simultaneously at a number of different stations, in addition to relating each vertical structure to particular modes. Up to now, however, most of available data for such a comparison have been confined to the mid-latitude stations, and very sparse in the tropical region.

In this study, an attempt is made for some direct comparisons of the lower stratospheric and mesospheric winds and tides observed on 19-21 or 23 November 1981 by the VHF radars at Jicamarca $\left(11.95^{\circ} \mathrm{S}, 76.87^{\circ} \mathrm{W}\right)$ and Arecibo $\left(18.35^{\circ} \mathrm{N}, 66.75^{\circ} \mathrm{W}\right)$, which are located at the nearly conjugate geographic points across the equator. This synchronous observation was carried out during the core period of the global campaign from 19 November to 3 December 1981, as had been recommended by the ICMUA (International Commission on the Meteorology of the Upper Atmosphere)-IAGA (International Association of Geomagnetism and Aeronomy) working group on atmospheric tides. Discussion on the vertical structure of tides is made comparing observational results with theoretical model. As for the stratospheric wind motions at Arecibo, long-period gravity waves with very short vertical wavelength are eliminated with the aid of numerical filtering. Sparsity of the mesospheric wind data at Arecibo is complemented by those observed by last long-term campaign in the same season (RÖTTGER et al., 1983).

\section{Observational Technique and Data Reduction}

At Jicamarca, three daytime (0600-1800 LT) runs for the lower stratosphere $(15-30 \mathrm{~km}, 7$ altitudes) and the mesosphere $(60-90 \mathrm{~km}, 13$ altitudes) were performed by the use of the high-power $50 \mathrm{MHz}$ radar during 19-21 November 1981. In this experiment, we mainly adopted the observational set-up used by the Kyoto University group for the previous lower stratospheric and mesospheric wind measurements in 1977 (FUKAO et al., 1980a, b, 1981b). Two beams, i.e., vertical (FLEISCH, 1976) and off-vertical $\left(3.45^{\circ}\right.$ westward, $0.15^{\circ}$ northward) were simultaneously employed using two orthogonal NE and NW arrays, respectively. Both line-of-sight velocities of vertical and off-vertical directions were deduced from the first moment of the power spectra of received signals at intervals of about $1.2 \mathrm{~min}$. Zonal wind velocities are then calculated from the difference between two line-of-sight velocities averaged over one hour.

In the Arecibo experiment, the SOUSY-VHF radar $(46.8 \mathrm{MHz})$ was operated with the Arecibo Observatory antenna dish. Detailed descriptions of the observational techniques are given elsewhere (RÖTTGER et al., 1981, 1983). Above the 
height of $11 \mathrm{~km}, 105$ height levels were sampled with an altitude resolution of $1.2 \mathrm{~km}$, which was achieved by a 8-bit complementary code. Significant echoes were obtained in the height range of $15-35 \mathrm{~km}$ for the stratosphere and $65-80$ $\mathrm{km}$ for the mesosphere, respectively. Both zonal and meridional winds were observed every two hours by steering a beam alternately between two directions. The wind measurements were performed almost continuously during the period from 0730 LT on 19 to 1100 LT on 23 November 1981.

\section{Lower Stratospheric Winds and Tides}

Vertical profiles of zonal wind (westerly positive) averaged over the whole observational period are shown for Arecibo (left) and Jicamarca (right) in Fig. 1. Horizontal bars attached to the data points signify the standard deviation of fluctuating components around the averaged values. A dashed line indicates the zonal wind observed by the rawinsonde at San Juan, Puerto Rico $(80 \mathrm{~km}$ east of Arecibo) during 20-22 November 1981. At Jicamarca, easterly winds with the values of $10-20 \mathrm{~m} \mathrm{~s}^{-1}$ exist in the lower stratosphere. At Arecibo, on the other hand, zonal winds almost cease in the lower stratosphere. Thus, the observed zonal wind profiles are different between the two stations. These structures in the wind profiles at Jicamarca $\left(12^{\circ} \mathrm{S}\right)$ and Arecibo $\left(18^{\circ} \mathrm{N}\right)$ are generally in good agreement with characteristics of climatological mean zonal wind profile at the corresponding latitude in the summer and winter hemisphere, respectively (cf., CIRA, 1972).
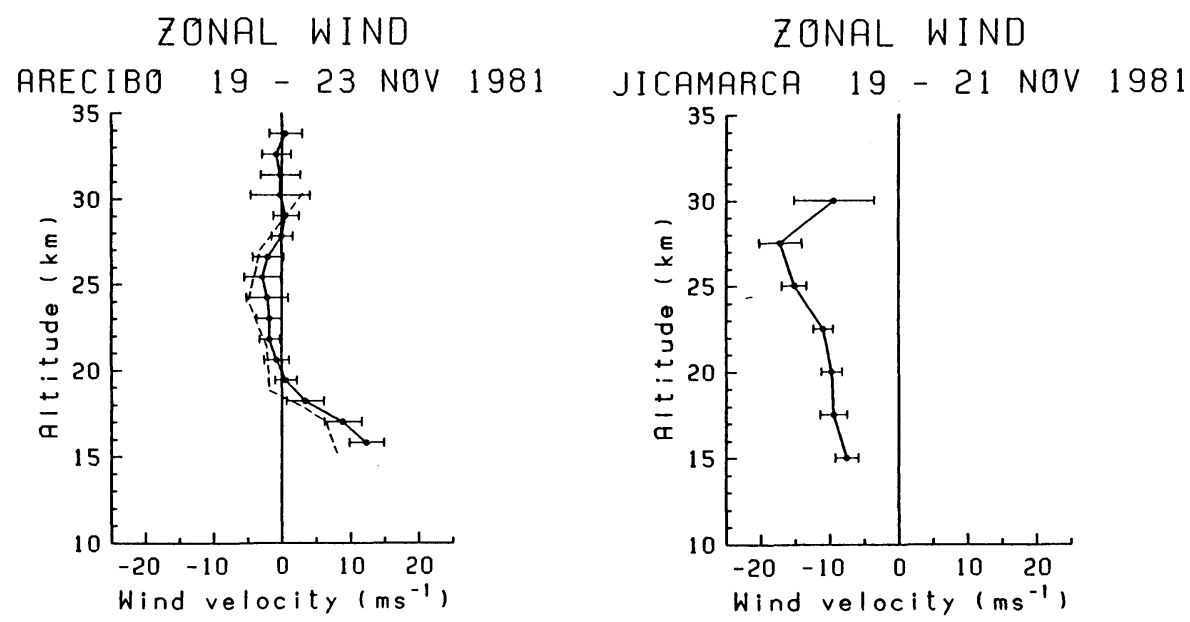

Fig. 1. Vertical profiles of zonal wind (positive westerly) in the lower stratosphere averaged over whole observational period at Arecibo $\left(18^{\circ} \mathrm{N}\right.$; left) and Jicamarca $\left(12^{\circ} \mathrm{S}\right.$; right). Horizontal bars attached to the data point denote the standard deviation of the fluctuating components around the averaged values. A dashed line indicates the zonal wind observed by the rawinsonde at San Juan, Puerto Rico (80 km east of Arecibo) during 20-22 November 1981. 
Figure 2 gives time-height sections of fluctuating wind components around the averaged values for Arecibo (top) and Jicamarca (bottom). The contour lines are drawn at $1 \mathrm{~m} \mathrm{~s}^{-1}$ interval with shaded areas indicating easterly winds. It can be seen that the characteristics of the wind fluctuation at Arecibo are different above and below $22 \mathrm{~km}$. In the upper region, the fluctuation has fairly large vertical scale, and shows a similar feature on each observational day. In
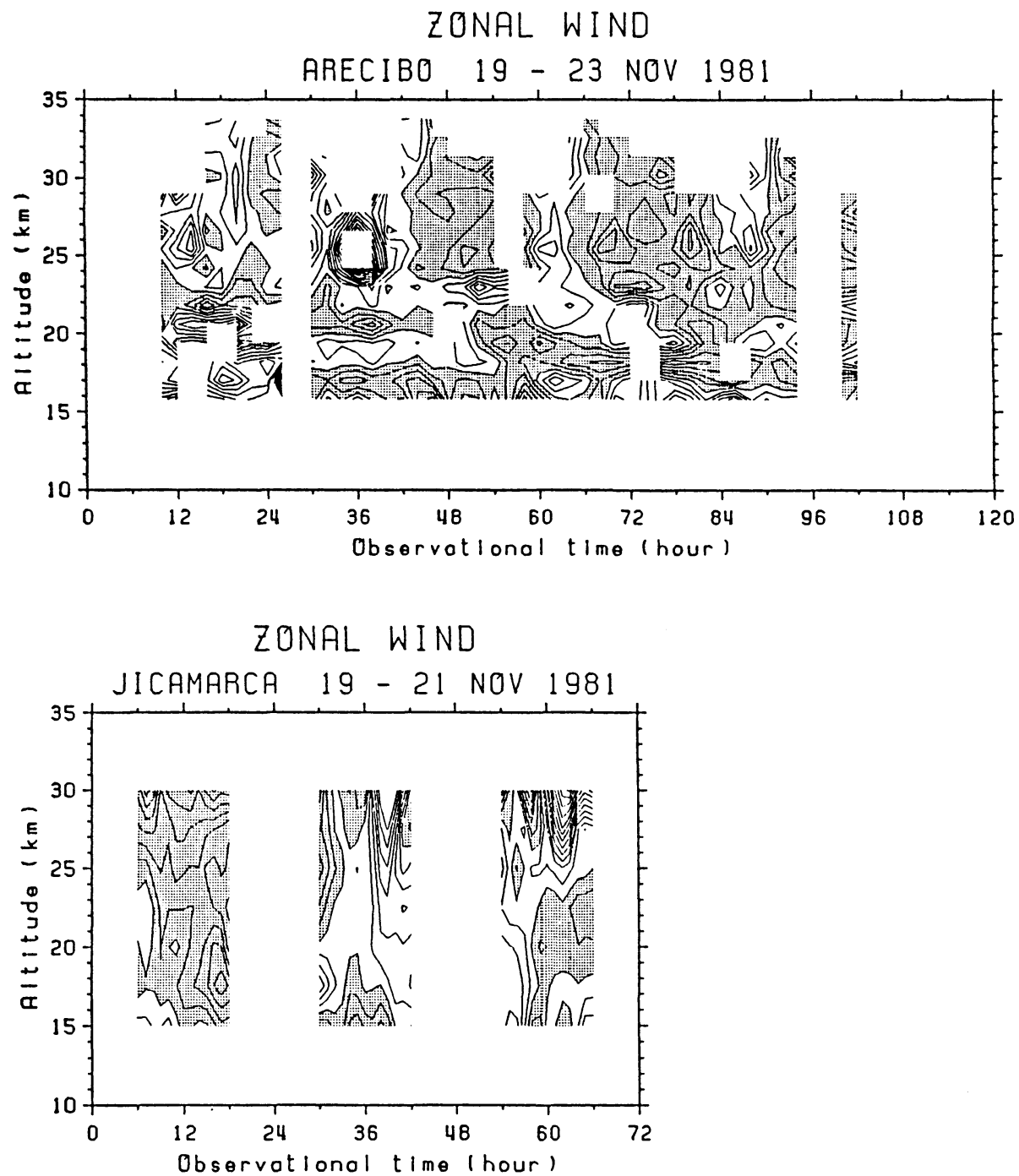

Fig. 2. Time-height sections of the fluctuating wind components around the averaged values at Arecibo $\left(18^{\circ} \mathrm{N}\right.$; top) and Jicamarca $\left(12^{\circ} \mathrm{S}\right.$; bottom) in the lower stratospheric region. The contour lines are drawn at $1 \mathrm{~m} \mathrm{~s}^{-1}$ intervals with shaded areas indicating easterly winds. 
the lower region, the fluctuation having much smaller vertical scale (less than $5 \mathrm{~km}$ ) and a time scale longer than one day appears to be dominant. At Jicamarca, the data span of each observational day is limited to daytime hours, so that estimation of dominant time scale of the wind fluctuation is not so straightforward as in the case of Arecibo.

As shown in Fig. 2 the Arecibo data contains larger and smaller verticalscale wind fluctuations. Note that each fluctuation has considerably different time scale. We separate them by numerical filtering in the vertical direction, making use of fine altitude resolution of the Arecibo radar. Cut-off vertical wavelength used for the filter is $6 \mathrm{~km}$ ( 5 height levels). Then, power spectra of temporal variation of the wind velocities are calculated by the complex MEM algorithm (HAYASHI, 1977) for the two regimes of vertical-scale fluctuation. The zonal and meridional wind components are here considered as real and imaginary parts of complex time series, respectively. This gives the sense of rotation of the horizontal velocity vector as well as relevant periods. The resultant vertical distributions of power spectra for the larger and smaller vertical-scale fluctuations are presented in Figs. 3 (a) and (b), respectively. The negative (positive) frequency means the (anti-) clockwise rotation of the wind velocity vector when continuously observed at a fixed point. The contours are drawn at $5 \mathrm{~dB}$ intervals. Figure 3 (a) as a whole shows isolated spectral peaks at \pm 1 and \pm 2 cycles per day, while the periods deduced from the spectral peaks in Fig. 3(b) is around 2 days. It is then inferred that tidal components are included in the wind fluctuations with vertical scale larger than $6 \mathrm{~km}$. On the other hand, quasi-periodic oscillations with vertical scale smaller than $6 \mathrm{~km}$ are possibly due to a longperiod internal inertia-gravity wave (CADET and TeItelbaUM, 1979; SATO and WOODMAN, 1982; MAEKAWA et al., 1984), which is characteristic of the tropical wind motions. The appearance of the spectral peaks only on the negative-frequency regime indicates clockwise rotation of the wind velocity vector, being consistent with the internal inertia-gravity wave in the northern hemisphere.

Next, combination of 24 and $12 \mathrm{~h}$ sinusoids is fitted to the filtered wind fluctuations at Arecibo with vertical scale larger than $6 \mathrm{~km}$. Figure 4 displays amplitudes and phases of the resulting tidal components at each observational height. Thick and thin lines indicate the zonal and meridional components of diurnal and semidiurnal tides, and horizontal bars mean the estimation errors of each tidal parameter. The scale of meridional phase is shifted by $90^{\circ}$ so as to clarify a phase quadrature relationship. The meridional phase overlaps with the zonal one in this diagram in case that the associated wind velocity vector rotates clockwise. Theoretical model values after FORBES $(1982 \mathrm{a}, \mathrm{b})$ are shown in the diagram by circles (zonal) and crosses (meridional). These values are taken for $18^{\circ} \mathrm{N}$ at the December solstice. It is seen from Fig. 4 that the observed diurnal amplitudes increase with increasing height, and that its phases on the whole show downward propagation in the height range considered. On the other hand, the observed amplitudes and phases of the semidiurnal tide do not show so much variation with respect to height as those of the diurnal tide. These tidal features 

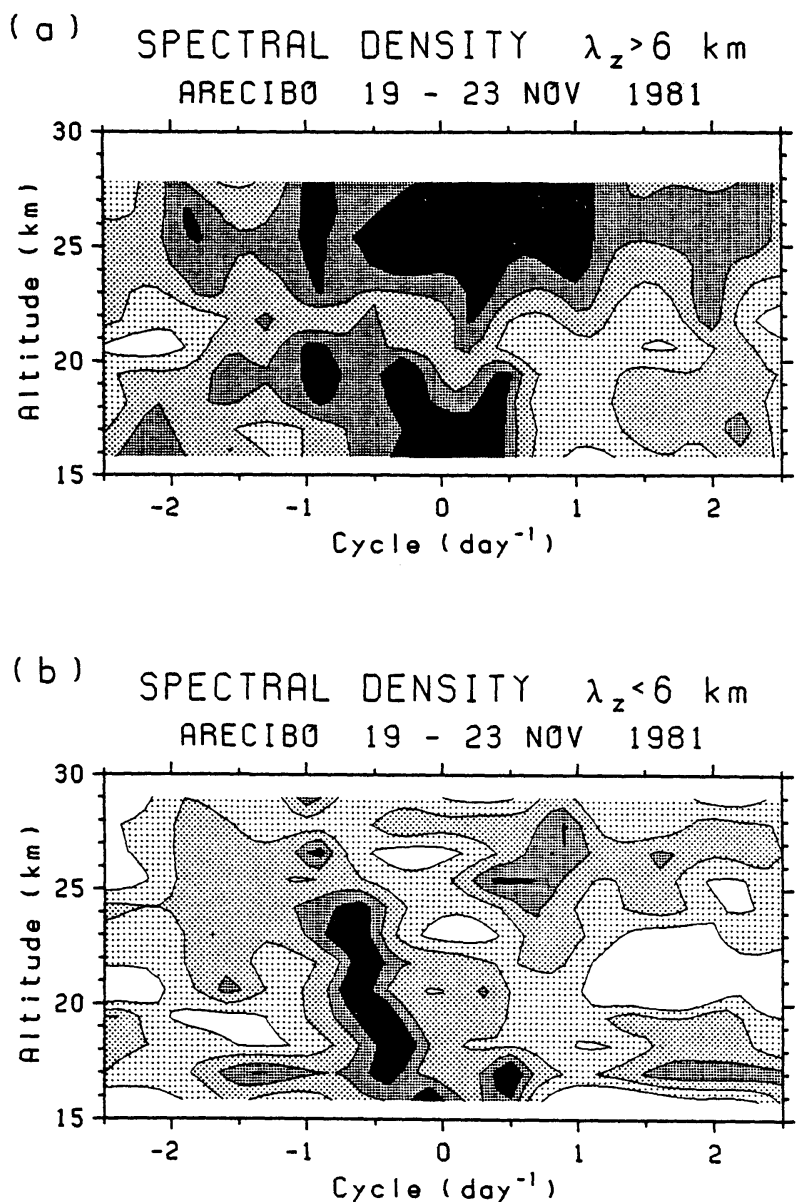

Fig. 3. Height distributions of the frequency power spectra (per day) of the wind fluctuations at Arecibo $\left(18^{\circ} \mathrm{N}\right)$ in the lower stratosphere. The results for the longer $\left(\lambda_{z}>6 \mathrm{~km}\right)$ and shorter $\left(\lambda_{z}<6 \mathrm{~km}\right)$ vertical-scale fluctuations are presented in (a) and (b), respectively. The negative (positive) frequency means the (anti-) clockwise rotation of wind velocity vector with time at a fixed point. Diurnal and semidiurnal oscillations correspond to frequencies of \pm 1 and \pm 2 cycles per day, respectively. The contours are drawn at $5 \mathrm{~dB}$ intervals.

are qualitatively in agreement with the theoretical model. Inspection of the vertical structure of the observed diurnal tide, however, shows that a node appears for the amplitude in the vicinity of $22 \mathrm{~km}$, where the sense of rotation of wind vector is largely reversed from the clockwise rotation of the theoretical model. The vertical scale of the fluctuating component superimposed is inferred to be about $10 \mathrm{~km}$ from its phase profile. The reversal of polarization is also confirmed by the enhancement of positive frequency component in Fig. 3 (a). This is related to the tidal characteristics which are not included in the theoretical model. 


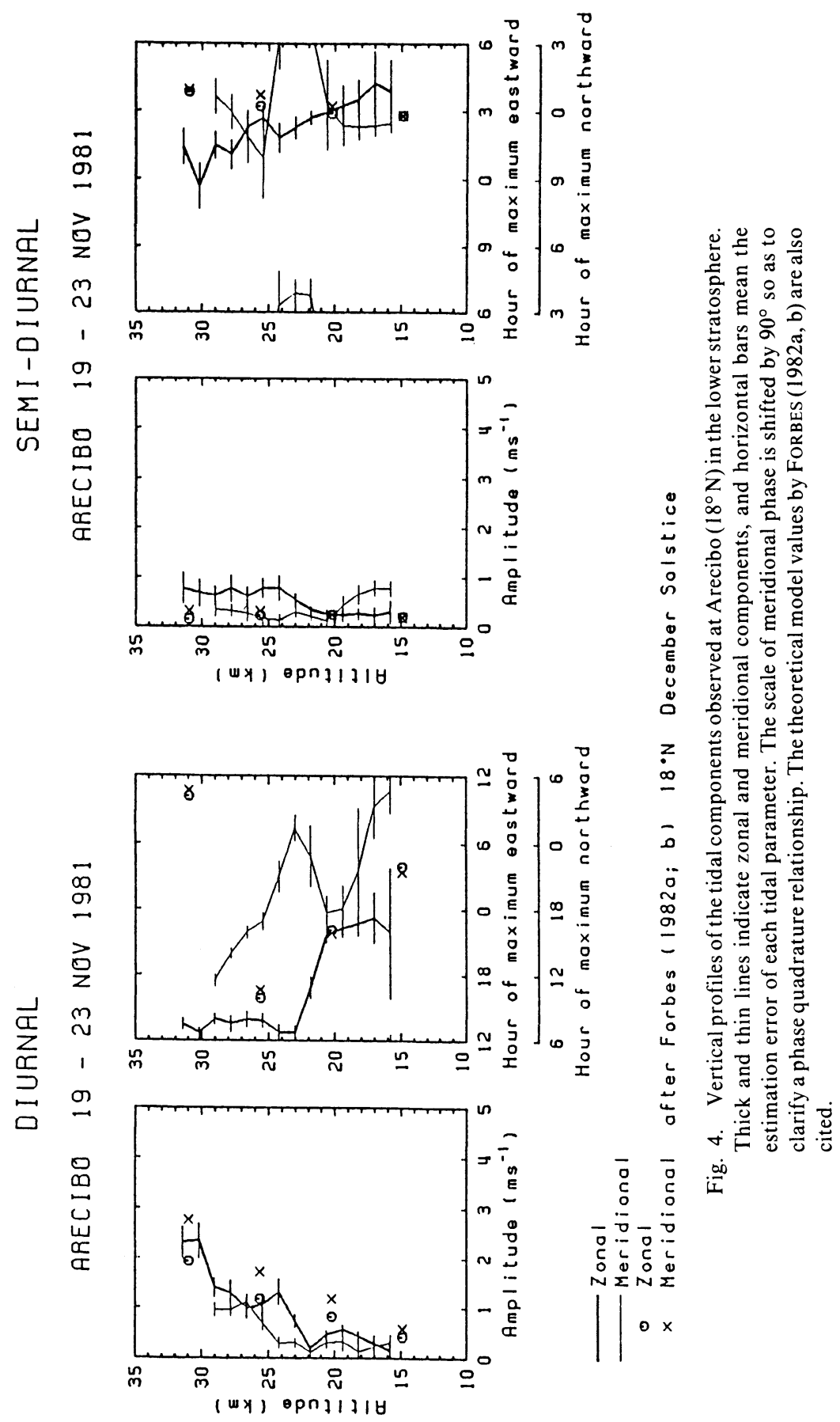


Therefore, we must take into account higher-order modes which are possibly due to non-migrating tides, in order to explain these observational results (FUKAO et al., 1980c; KATO et al., 1982).

In case of Jicamarca, it is not so easy to deduce both diurnal and semidiurnal tides simultaneously and unambiguously from the lower stratospheric winds, due to the limited data span of 12-13 h per day. As an alternative approach, at the moment, we compare the daytime wind variations of Jicamarca with those of Arecibo. Figure 5 shows the time-height section of the hourly values averaged
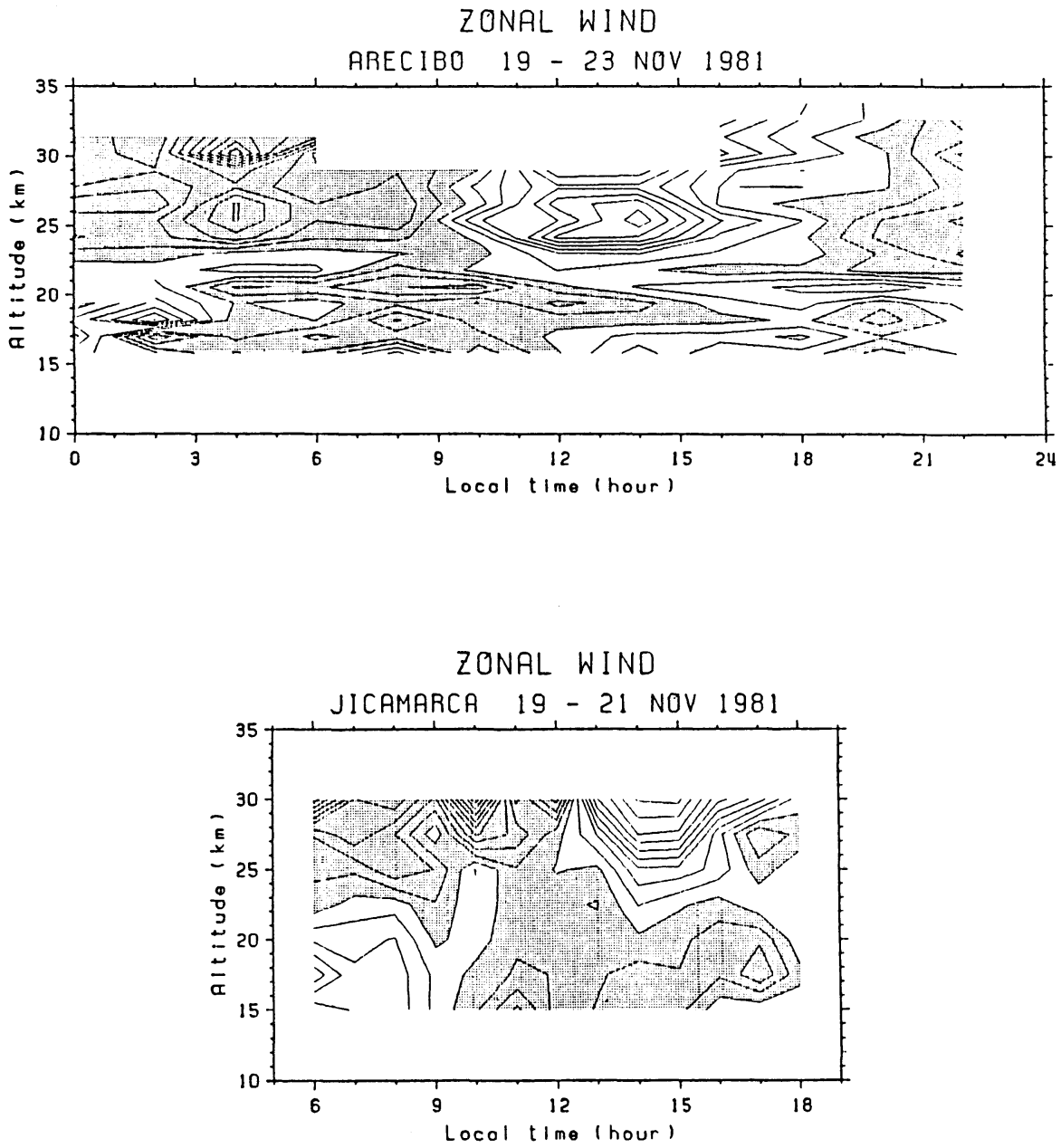

Fig. 5. Time-height sections of the hourly values averaged over all observational days at Arecibo $\left(18^{\circ} \mathrm{N}\right.$; top) and Jicamarca $\left(12^{\circ} \mathrm{S}\right.$; bottom) in the lower stratosphere. The contour intervals are $0.5 \mathrm{~m} \mathrm{~s}^{-1}$ and the shaded areas indicate easterly winds. 
over all observational days at Arecibo (top) and Jicamarca (bottom). It is found that the lower stratospheric wind variations of both stations are similar in daytime at least above the height of $22 \mathrm{~km}$ where the diurnal tide dominates at Arecibo. We can thus infer that diurnal tides are dominant in the hourly wind values observed at Jicamarca as well as at Arecibo. In this connection, the diurnal tides may be estimated by a least-mean-square fitting without significant contamination by semidiurnal tides.

Figure 6 shows the vertical profiles of the resulting diurnal amplitude and phase. The theoretical values after Forbes $(1982 \mathrm{a}, \mathrm{b})$ are shown for $12^{\circ} \mathrm{S}$ at the December solstice. In general, consistency with the theoretical model is fairly well found in the phase profile. The result is also similar to the lower stratospheric tidal feature obtained by the previous experiments at Jicamarca in 1977 (FUKAO et al., 1981a, b), although the amplitude is estimated to be fairly larger in the present observation. Furthermore, it is very interesting that a detailed vertical structure, such as a node of the amplitude and a rapid phase shift around 22 $\mathrm{km}$ height, is well correlated with that of Arecibo shown in Fig. 4. The present synchronous observation thus shows a close relationship of the lower-stratospheric diurnal tides across the equator.

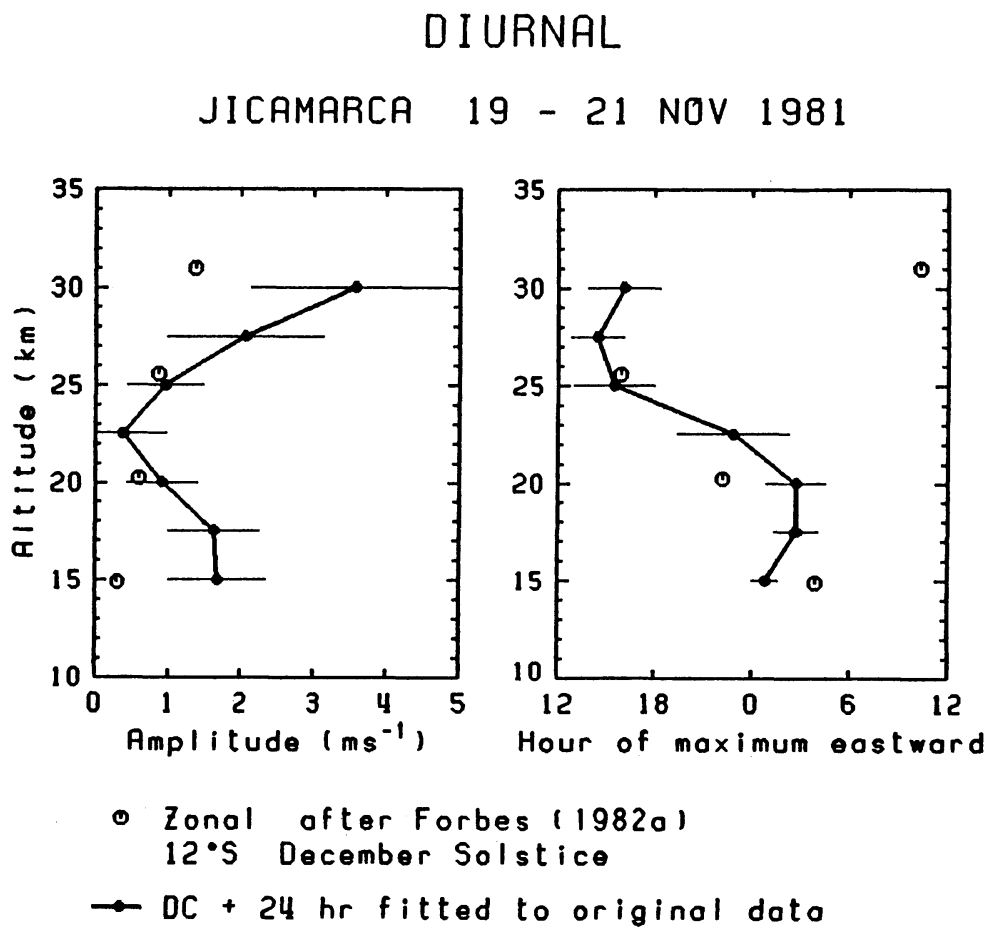

Fig. 6. Vertical profile of the zonal component of the lower stratospheric diurnal tide observed at Jicamarca $\left(12^{\circ} \mathrm{S}\right)$. The horizontal bars denote the estimation error of each parameter. 
4. Mesospheric Winds and Tides

Figure 7 shows a vertical profile of zonal wind averaged over three sets of daytime hours at Jicamarca. Also shown are the profiles of the mesospheric DC values inferred from the tidal analysis using various fitting procedures as will be discussed later. These results almost lie within the range of indicated error bars, giving no substantial change. For comparison, thin lines denote zonal wind velocities measured by the meteorological rocket soundings around the obser-

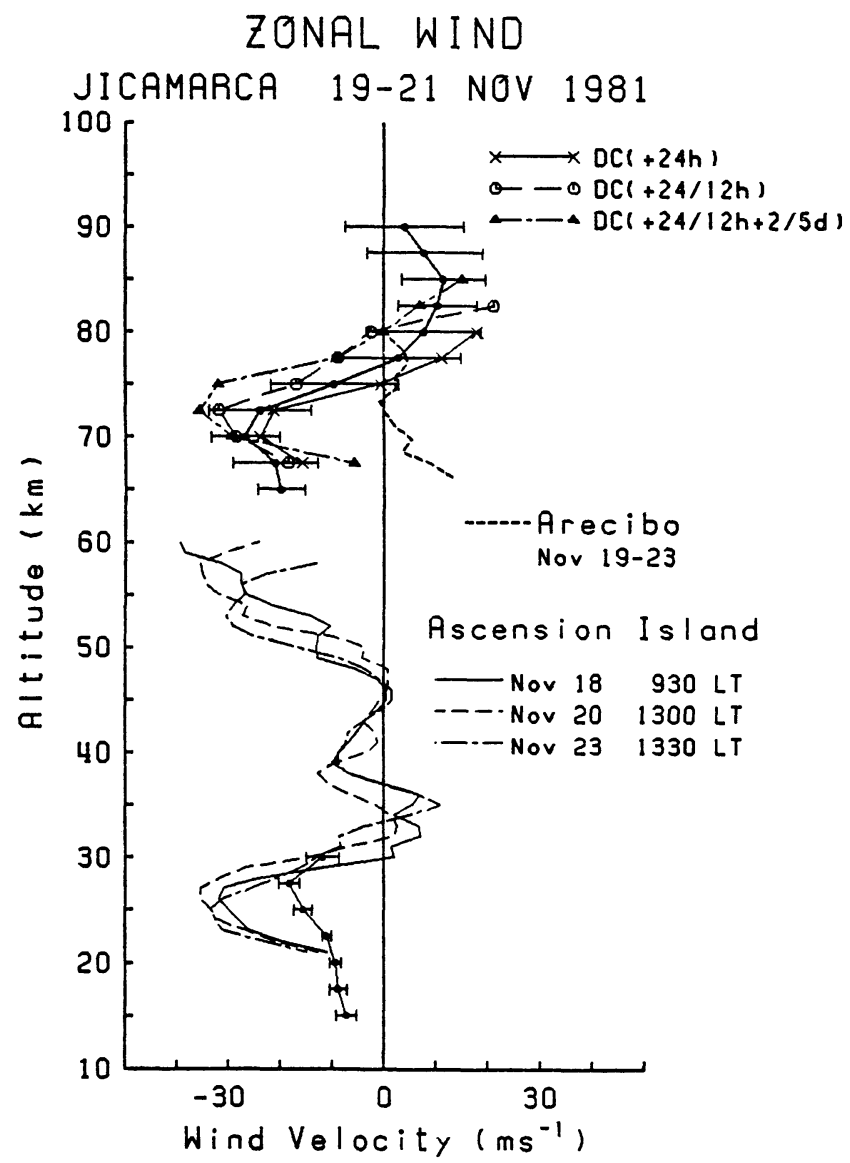

Fig. 7. Vertical profile of the averaged zonal wind (positive westerly) observed at Jicamarca $\left(12^{\circ} \mathrm{S}\right)$ in the mesosphere and lower stratosphere. The horizontal bars denote the standard deviation of the fluctuating components. Also shown are the profiles of the mesospheric DC values inferred from the tidal analysis using various fitting procedures. A dashed line indicates a profiles for the Arecibo mesosphere. Thin lines below $60 \mathrm{~km}$ show zonal wind velocities measured by the meteorological rocket soundings at Ascension Island $\left(8.0^{\circ} \mathrm{S}, 14.4^{\circ} \mathrm{W}\right)$ around the present observational period. 
vational period at Ascension Island $\left(8.0^{\circ} \mathrm{S}, 14.4^{\circ} \mathrm{W}\right)$, which is located at a latitude similar to Jicamarca. The lower stratospheric mean wind at Jicamarca is also shown in the lower part of the diagram. It is seen from the figure that the summer easterlies are dominant up to $70 \mathrm{~km}$ at about $10^{\circ} \mathrm{S}$ latitude. A distinct reversal of the wind direction from easterly to westerly with increasing altitude is clearly observed in the vicinity of $77 \mathrm{~km}$ height.

Such a summer reversal in the tropical mesosphere was also reported by the meteor radar at Punta Borinquen $\left(18^{\circ} \mathrm{N}\right.$; MASSEBEUF et al., 1981), the partial reflection drift radar at Townsville $\left(19^{\circ} \mathrm{S}\right.$; VINCENT and BALL, 1981), and the Arecibo UHF radar $\left(18^{\circ} \mathrm{N}\right.$; HIROTA et al., 1983). Considering that the heights of reversal obtained from these other observations are around $85 \mathrm{~km}$, the corresponding height of the present observation is somewhat lower. It is here noted that the westerly maximum of the equatorial semiannual oscillation appears around $80 \mathrm{~km}$ in November or December (see a review of HiRota (1980), for example). Since the Jicamarca radar is located more equatorward by $6-7^{\circ}$ than the other stations, westerly winds of about $10 \mathrm{~m} \mathrm{~s}^{-1}$ is expected to be superimposed on the mean zonal wind, giving the reversal descent in the present observation. At Arecibo, in contrast, the mean zonal wind shown in Fig. 7 by a dashed line is fairly small (less than $10 \mathrm{~m} \mathrm{~s}^{-1}$ ) at the $65-80 \mathrm{~km}$ height as well as the lower stratosphere, and does not indicate a clear reversal.

Figure 8 depicts a time-height diagram of the hourly values averaged over the consecutive three days at Jicamarca. The contour lines are drawn at $2 \mathrm{~m}$ $\mathrm{s}^{-1}$ intervals and the shaded areas indicate easterly winds. In this figure, tidal components which would have a constant phase on each day are expected to be predominant, as was done in Fig. 5. The local-time, hourly wind variation generally shows downward phase propagation which is roughly estimated to be $20 \mathrm{~km}$ (from 90 - to $70-\mathrm{km}$ height) between $8 \mathrm{LT}$ and $14 \mathrm{LT}$. This apparent phase propagation yields vertical wavelengths of $80 \mathrm{~km}$ or $40 \mathrm{~km}$ for diurnal or semidiurnal tide, respectively. But, these values are not directly related to any of the fundamental, vertically-propagating modes, such as $S_{1,1}$ or $S_{2,2}$. Therefore, the observed vertical structure may be rather explained in terms of mixture of both diurnal and semidiurnal components. This result is not necessarily consistent with those predicted by tidal theories (ForBES, 1982a, b), which show the dominance of vertically propagating diurnal tide in the tropical mesosphere (3-4 times larger than semidiurnal tide). However, CounTRYMAN and Dolas (1982) have shown that both zonal and meridional amplitudes of the mesospheric diurnal tides are $10-20 \mathrm{~m} \mathrm{~s}^{-1}$ and comparable to those of semidiurnal tides in every season at Jicamarca. Also, the present result is consistent with earlier observations by WOODMAN and GUILLÉN (1974) and HARPER and WOODMAN (1977).

As was already mentioned in the case of the lower stratospheric wind data at Jicamarca, tidal analysis of both diurnal and semidiurnal components should be carefully performed for the daytime data span. Following COUNTRYMAN and Dolas (1982), we tried several methods using various fitting procedures, such as $\mathrm{DC}+24$ and/or $12 \mathrm{~h}, \mathrm{DC}+24 / 12 \mathrm{~h}+2 / 5$ days and so on (2-day and 5-day 


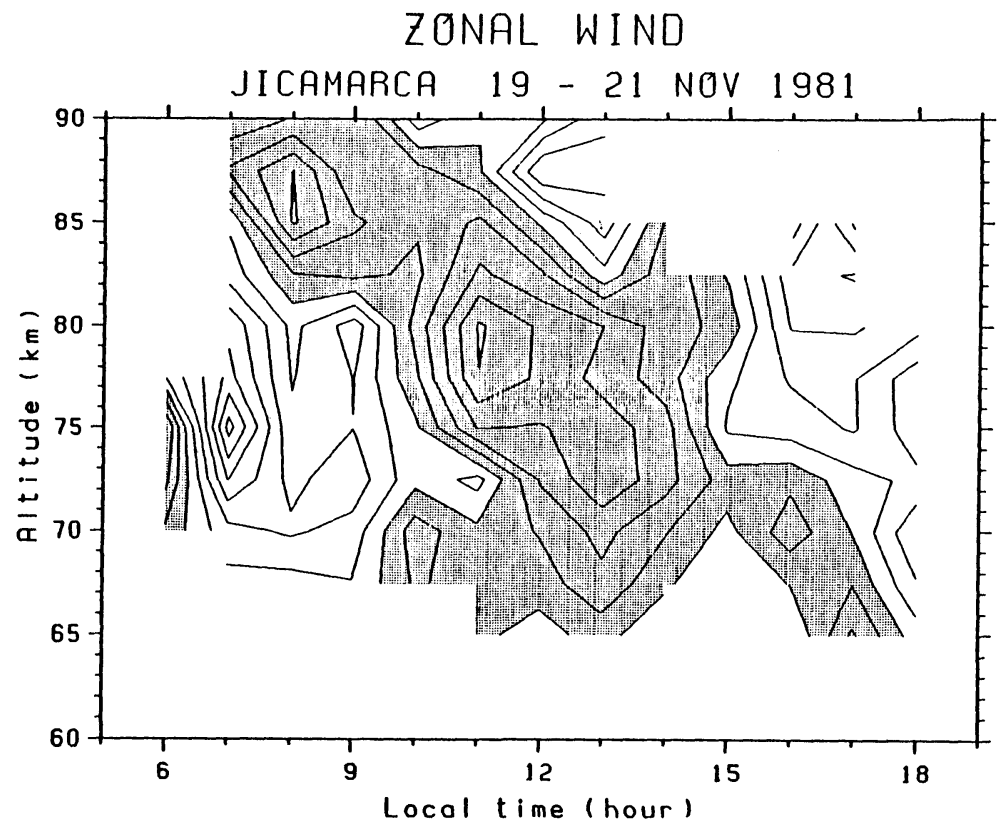

Fig. 8. Time-height diagram of the hourly values averaged over the consecutive three days in the mesosphere over Jicamarca $\left(12^{\circ} \mathrm{S}\right)$. The contour lines are drawn at $2 \mathrm{~m} \mathrm{~s}^{-1}$ intervals and the shaded areas indicate easterly winds.

oscillations are considered to be also significant in the mesosphere, e.g., SALBY and RoPER, 1980; MASSEBEUF et al., 1981). Moreover, fitting is made in case that the nighttime data is set to be zero, in order to prevent an extreme interpolation of the missing nighttime data. The representative results are shown in Fig. 9 for the semidiurnal component between 67.5 and $80 \mathrm{~km}$, where almost continuous wind data are available during 12-h daytime hours. Its vertical structure, especially its phase, is consistently inferred by the various fitting methods. The dashed lines show the value observed by CounTRYMAN and Dolas (1982) in the same season. The open circle denotes the theoretical model after FORBES (1982b) for $12^{\circ} \mathrm{S}$ at the December solstice. It is found that the observed semidiurnal tide agrees fairly well with the theoretical values, although its phase deviates by about three hours in the upper height region. The result is also consistent with those previously observed by Countryman and Dolas at Jicamarca. As for the diurnal tide, on the other hand, the tidal analysis yields different results on its phase profile according to each fitting function, so that its vertical structure is not exactly deduced. Hence, it is uncertain that the diurnal tide is dominant in the mesospheric wind field at Jicamarca.

Because of weaker echoes, the data rate is fairly lower in time and height at Arecibo than at Jicamarca as shown in Fig. 10, so that a detailed tidal analysis 


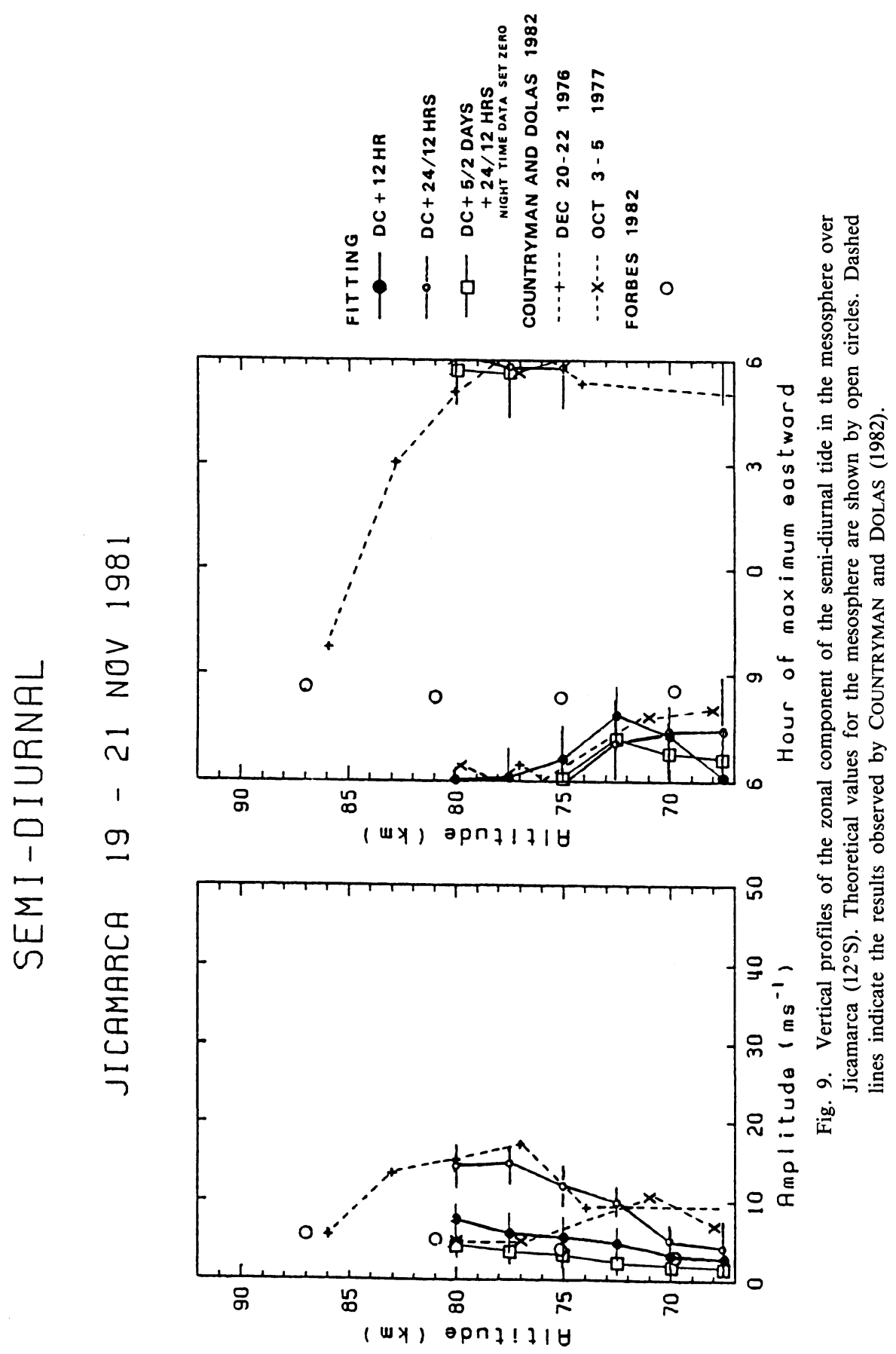




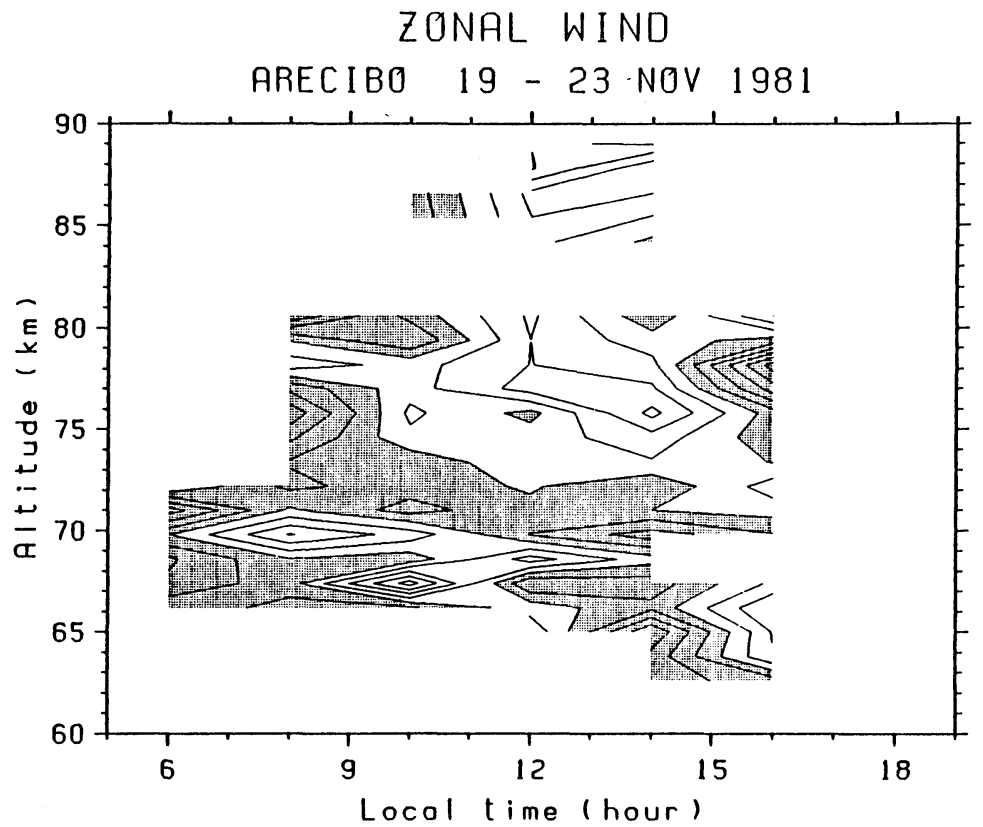

Fig. 10. Same as Fig. 8 except for the mesospheric winds at Arecibo $\left(18^{\circ} \mathrm{N}\right)$.

is more difficult. In the observed height range of $65-80 \mathrm{~km}$, the characteristics of wind fluctuations are considerably different from that of Jicamarca; in particular their vertical scale is fairly smaller $(10-20 \mathrm{~km})$. Thus, a common tidal feature is not so clearly detected by comparing, as was done in the lower stratosphere (Fig. 5), the daytime wind variations between both stations (Figs. 8 and 10). In addition to the tidal wind, recent mesospheric observations (VINCENT, 1984; MAEKAWA et al., 1986) show that internal inertia-gravity waves with periods around one day dominate the tropical wind field in the height range considered. Such long-period gravity waves are characterized by amplitude of $20-30 \mathrm{~m} \mathrm{~s}^{-1}$ and vertical wavelength of $10-20 \mathrm{~km}$. It is probable in the present Arecibo observation that these wave components with random phase are, if they exist, not sufficiently subtracted from the averaged hourly wind values shown in Fig. 10, since the effective data points are fairly sparse during the consecutive five days. Therefore, we cannot conclude the observed smaller verticalscale wind fluctuations to be a tidal feature based on these data alone.

RÖTTGER et al. (1983) have reported a quasi-wavelike pattern in vertical profiles of both zonal and meridional wind velocities averaged at a particular local time on successive 32 days during the earlier campaign (December 1980/January 1981) of the VHF radar observations at Arecibo, and pointed out that its characteristic is generally consistent with the vertically propagating diurnal tide (see Fig. 4 of RöTTGER et al., 1983). Hence, the present VHF radar observation 
in the same winter season is considered to show a similar characteristic of diurnal phase propagation to some extent, although only a limited portion of the oscillation can be detected. In addition, a number of evidences have been reported on the existence of the vertically propagating diurnal tides using the incoherent scatter technique of the Arecibo UHF radar (MATHEwS, 1976; FuKUYAMA, 1981; HiROTA et al., 1983; MAEKAWA et al., 1985), which can be easily detected by the phase propagation during the daytime hour observations. The meteor radar observations at Punta Borinquen near Arecibo (BERNARD et al., 1981) also support this assertion in every season.

\section{Summary and Concluding Remarks}

The vertical structure of averaged zonal wind and tidal components in the tropical lower stratosphere and mesosphere has been discussed based on the hourly wind data observed by the Jicamarca $\left(12^{\circ} \mathrm{S}\right)$ and Arecibo $\left(18^{\circ} \mathrm{N}\right)$ VHF radars. In the lower stratosphere, the zonal component of diurnal tides shows a similar feature between Jicamarca and Arecibo, while the mean zonal wind profiles differ largely between the two stations. It should be noted that a good correspondence is found between detailed vertical structures of the diurnal tides at both stations, suggesting the symmetric nature of the tidal wind field across the equator.

In the case of Arecibo, the separation of tidal modes and long-period gravity waves is pursued, making use of the fine altitude resolution and vectorial representation of zonal and meridional winds. It is found that a characteristic wave period is clearly distinguished between the wind motions with vertical scales larger and smaller than $6 \mathrm{~km}$, which mainly contain the tidal modes and the internal inertia-gravity waves, respectively. In consequence of harmonic fitting procedure, vertical scale of the tidal components proves to be longer than about $10 \mathrm{~km}$, which is qualitatively reasonable considering the coexistence of higherorder and/or nonmigrating tidal modes (KATO et al., 1982). This result is also consistent with the long-term rawinsonde observation presented by WALLACE and TADD (1974) at low to mid-latitude.

The mesospheric tides show a different feature between Arecibo and Jicamarca in contrast to the lower stratospheric ones. At Jicamarca, vertically propagating diurnal tide is not so clearly detected, though the wind variation (Fig. 8) is not inconsistent with the theoretical prediction that the easterly wind, for example, maximizes at around noon at about $73 \mathrm{~km}$ (ForBES, 1982a). Tidal analysis gives a semidiurnal component, which generally agrees with the theory (FORBES, 1982b). On the other hand, the Arecibo VHF radar observation shows a possible existence of the propagating diurnal tide, in the light of its previous long-term campaign (RöTTGER et al., 1983). The tidal amplitude inferred from the vertical profiles of wind velocities in the previous campaign is, for example, about 10 $\mathrm{m} \mathrm{s}^{-1}$ at $78 \mathrm{~km}$, being fairly smaller than the theoretical values of $25-30 \mathrm{~m}$ $\mathrm{s}^{-1}$ for diurnal tide. Thus, the present observational results at both stations suggest a variable nature of the mesospheric diurnal tide, while the lower stratospheric 
diurnal tide is shown to be dominant and fairly stable.

There will be of course a need for further observations and discussions in order to clarify the global tidal structure throughout the middle atmosphere. A broader radar network is highly desirable in the tropical region. Also it is worthwhile to compare the mesospheric observations by the VHF/UHF radars with the upper mesospheric and lower thermospheric ones $(80-110 \mathrm{~km})$ by MF radars and meteor radars which can obtain continuous nighttime wind data.

The authors thank the staffs of the Jicamarca Radio Observatory, the Arecibo Observatory and the Max-Planck-institut für Aeronimie for their helpful cooperation. Thanks are given to Dr. S. Fukao and Dr. K. Wakasugi who offered a lot of information on the previous lower stratospheric and mesospheric observations at Jicamarca. Thanks are also due to Prof. J. M. Forbes who kindly sent a detailed table of the theoretical tidal calculation. Meteorological rocket data were supplied by courtesy of the Aerological Division of Japan Meteorological Agency. Also, rawinsonde data were supplied by the National Weather Service's routine observation at San Juan, Puerto Rico. Jicamarca experiments and related collaborations were supported by the Nissan Science Foundation. The Jicamarca Radio Observatory is operated by the Instituto Geofisico del Peru. The Arecibo Observatory is operated by Cornell University under contract with the U.S. National Science Foundation.

\section{REFERENCES}

AHMED, M. I. and R. G. ROPER, The diurnal and semidiurnal oscillations in meteor winds over Atlanta, J. Atmos. Terr. Phys., 45, 181-192, 1983.

Bernard, R., J. L. Fellous, M. MASSEbeuf, and M. Glass, Simultaneous meteor radar observations at Monpazier (France, $45^{\circ} \mathrm{N}$ ) and Punta Borinquen (Puerto-Rico, $18^{\circ} \mathrm{N}$ ): 1-Latitudal variations of atmospheric tides, J. Atmos. Terr. Phys., 43, 522-533, 1981.

CADET, D. and H. TeITElbaUM, Observational evidence of internal inertia-gravity waves in the tropical stratosphere, J. Atmos. Sci., 36, 892-907, 1979.

CIRA, COSPAR International Reference Atmosphere, 450 pp., Akademie-Verlag, Berlin, 1972.

Countryman, I. D. and P. M. Dolas, Observations on tides in the equatorial mesosphere, $J$. Geophys. Res., 87, 1336-1342, 1982.

FLEISCH, D. A., Stratospheric scattering of radio waves and the Jicamarca radio telescope, M. S. Dissertation, Rice University, Houston, Texas, 1976.

FORBES, J. M., Atmospheric tides 1: Model description and results for the solar diurnal component, J. Geophys. Res., 87, 5222-5240, 1982a.

FORBES, J. M., Atmospheric tides 2: The solar and lunar semidiurnal components, J. Geophys. Res., 87, 5241-5252, 1982 b.

FukAO, S., T. SATO, R. M. HARPER, and S. KATO, Radio wave scattering from the tropical mesosphere observed with the Jicamarca radar, Radio Sci., 15, 447-457, 1980a.

FukAo, S., T. SATO, I. HiRotA, and S. KATO, A preliminary radar observation of long-period waves in the tropical mesosphere over Jicamarca, J. Geophys. Res., 85, 1955-1957, 1980 b.

FukaO, S., T. SATo, N. YAmasaki, R. M. HARPER, and S. KATO, Radar measurement of tidal winds at stratospheric heights over Arecibo, J. Atmos. Sci., 37, 2540-2544, 1980c.

FuKaO, S., K. AOKI, K. WAKASUGi, T. TsudA, S. KATO, and D. A. FleisCH, Some further results on the lower stratospheric winds and waves over Jicamarca, J. Atmos. Terr. Phys., 43, 649-661, 1981a.

FUKAO, S., Y. MAEKAWA, and S. KATO, A semidiurnal wind oscillation with short vertical wavelength observed in the tropical lower stratosphere, J. Geomag. Geoelectr., 33, 421-427, 
1981 b.

FUKUYAMA, K., Incoherent scatter radar observations of wavelike structures in the mesosphere over Arecibo, J. Geophys. Res., 86, 9152-9158, 1981.

HARPER, R. M. and R. F. WOODMAN, Preliminary multiheight radar observations of waves and winds in the mesosphere over Jicamarca, J. Atmos. Terr. Phys., 39, 959-963, 1977.

HAYASHI, Y., Space-time power spectral analysis using the maximum entropy method, J. Meteor. Soc. Japan, 55, 415-420, 1977.

HiRotA, I., Observational evidence of the semiannual oscillation in the tropical middle atmosphere-a review, Pure Appl. Geophys., 18, 217-238, 1980.

hirota, I., Y. Maekawa, S. Fukao, K. Fukuyama, M. P. Sulzer, J. L. Fellous, T. Tsuda, and S. KATO, Fifteen-day observation of mesospheric and lower thermospheric motions with the aid of the Arecibo UHF radar, J. Geophys. Res., 88, 6835-6842, 1983.

Kato, S., Atmospheric tides-a review, J. Atmos. Terr. Phys., 43, 491-493, 1981.

Kato, S., T. TsudA, and F. Watanabe, Thermal excitation of nonmigrating tides, J. Atmos. Terr. Phys., 44, 131-146, 1982.

MAEKAWA, Y., S. FUKAO, T. SATO, S. KATO, and R. F. WoOdMAN, Internal inertia-gravity waves in the tropical lower stratosphere observed by Arecibo radar, J. Atmos. Sci., 41, 2359-2367, 1984.

Maekawa, Y., S. Fukao, I. Hirota, M. P. Sulzer, and S. Kato, Some further results on the long-term mesospheric and lower thermospheric wind observation by the Arecibo UHF radar, submitted to $J$. Atmos. Terr. Phys., 1986.

Manson, A. H., C. E. MeEK, and J. B. Gregory, The semi-diurnal tide at the Equinox: MF radar observations for $1978-1982$ at Saskatoon $\left(52^{\circ} \mathrm{N}, 107^{\circ} \mathrm{W}\right)$, J. Atmos. Sci., 40, 969-976, 1983.

Massebeuf, M., R. Bernard, J. L. Fellous, and M. Glass, Simultaneous meteor radar observations at Monpazier (France, $45^{\circ} \mathrm{N}$ ) and Punta Borinquen (Puerto-Rico, $18^{\circ} \mathrm{N}$ ): 2-Mean zonal wind and long period waves, J. Atmos. Terr. Phys., 43, 535-542, 1981.

MATHEWS, J. D., Measurements of the diurnal tides in the 80- to $100-\mathrm{km}$ altitude range at Arecibo, J. Geophys. Res., 81, 4671-4677, 1976.

RötTGER, J., P. CZECHOWSKY, and G. SCHMIDT, First low-power VHF radar observations of tropospheric, stratospheric and mesospheric winds and turbulence at the Arecibo Observatory, J. Atmos. Terr. Phys., 43, 789-800, 1981.

RötTger, J., P. CZEChOWSKY, R. RüSTER, and G. SCHMIDT, VHF radar observations of wind velocities at the Arecibo Observatory, J. Geophys., 52, 1-6, 1983.

SAlby, M. L. and R. G. Roper, Long-peirod oscillations in the meteor region, J. Atmos. Sci., 37, 237-244, 1980.

SATO, T. and R. F. WoOdman, Fine altitude resolution radar observation of upper-tropospheric and lower-stratospheric winds and waves, J. Atmos. Sci., 39, 2539-2545, 1982.

TsudA, T., T. Aso, and S. KATO, Seasonal variation of solar atmospheric tides at meteor heights, J. Geomag. Geoelectr., 35, 65-86, 1983.

VInCEnt, R. A., Gravity-wave motions in the mesosphere, J. Atmos. Terr. Phys., 46, 119-128, 1984.

VINCENT, R. A. and S. M. BALL, Mesospheric winds at low-latitudes in the southern hemisphere, J. Geophys. Res., 86, 9159-9169, 1981.

WALlACE, J. M. and R. F. TADD, Some further results concerning the vertical structure of atmospheric tidal motion within the lowest 30 kilometers, Mon. Wea. Rev., 102, 795-803, 1974.

WoOdman, R. F. and A. Guillén, Radar observation of winds and turbulence in the stratosphere and mesosphere, J. Atmos. Sci., 31, 493-505, 1974. 